\title{
Teoría de la Forma
}

\author{
Por Jorge C. Muelle
}

\section{LOS OBIETOS ARTIFICIALES DEL PASADO}

Los estudios de difusión de formas artificiales son evidentemente estudios históricos menos difíciles de llevarse a cabo que los de difusión de ideas y actitudes. Son incompletos, es verdad, cuando se reducen sólo a trazar distribuciones de caracteres y ni siquiera se discierne la época a que puedan corresponder en determinados puntos geográficos. El arqueólogo es el que más ha abusado de esta práctica, y se explica, porque el arqueólogo no puede tratar sino exclusivamente con objetos. Es característica de alguno de ellos una prontitud para resolver los problemas que sus hallazgos planteanig asi, antelena imposibilidad de conexiones, se decide por orígenes múltiples de las invenciones fundamentales y descuenta la probabilidad de que la difusión de un objeto sobrepasa la del grupo que lo creó. Otros, menos serios, conectan hipotéticamente rasgos similares de pueblos antípodas, sin encontrar las pruebas que lo permitan.

El verdadero papel del arqueólogo no es especular sino aportar datos concretos, precisamente para apoyar o disipar cualquiera de esas teorías. Pero ha sucedido que sin esperar su maduración se han servido de ellas, y, así, la teoría de la evolución de formas artísticas ha servido para construir precipitadas cronologías que los datos de la estratigrafía deshacen después. Si una estratigrafía representa la secuencia histórica de un punto geográfico, debemos esperar en ella testimonios de difusión, y por lo tanto la estratigrafía no puede, sino muy excepcionalmente, revelar completa e ininterrumpida la evolución de un rasgo cultural. Es imposi- 
ble que el arreglo de series de museo, de lo simple a lo complejo, corresponda exactamente a la Kulturleben de un pueblo. Ni las cadenas progresivas ni las degenerativas estarán completas en un solo sitio, pues las probabilidades de intromisiones y de haber hecho en otro parte de su carrera, es grande. Entonces, algunos eslabones que falten en un sitio pueden haber quedado en el otro. Este razonamiento llevó a los evolucionistas a reconstruir las series tomando hechos de aquí y de allí. Su lógica era sana pero las reconstrucciones no se hicieron siguiendo un método rigurosamente histórico. El evolucionismo es un esquema que no podemos ver cumplido rígidamente en las sociedades. El pensamiento histórico que lo siguió sirvió para corregir sus excesos.

El arqueólogo hace sus reconstrucciones por inferencia, pues los materiales a su disposición son limitados. Los objetos artificiales del pasado no dicen gran cosa sino por comparación con los del presente. Es por eso que D. Randall-Mac Iver (1932) pudo decir que la Arqueología sin la Antropología, sería tuerta, y miope de su único ojo. Si una esferita perforada es un piruro, es porque conocemos las ruecas todavía en uso. Si un pedazo de metal es un anzuelo, lo es por comporación con los que todavía utilizamos. Y cuando no estamos familiarizados con una forma, nuestro juicio es cauto y se pregunta: ¿Para qué pudo servir?

Con el propósito de enriquecer-las experiencias del arqueólogo, algunos etnólogos han dedicado en los últimos tiempos una atención especial a los lobjetos laftificialess $\otimes$ "sus complicaciones espirituales. El hecho de no tratar "fósiles" sino una cultura viviente les permitió conocer mucho de los impulsos del artista, de las dificultades que debía vencer, etc. Estas últimas no eran simplemente de carácter técnico: las encuestas revelaron que había siempre una lucha entre los problemas meramente tecnológicos y el gusto tradicional, que no siempre se acomodaba a los recursos en uso. El trabajo de Ruth Bunzel ${ }^{1}$ es de los más ilustrativos sobre el particular.

Esta investigadora tuvo la oportunidad de interrogar a los alfareros zuñi respecto a lo que consideraban bello y feo, al porqué de lo que rechazaban o aceptaban en un motivo extranjero, y a otras condiciones de sus gustos. Encontró que no siempre los

1 The Pueblo Potter, Columbia University Contributions to Anthropology, v. VIIII. 
artistas son conscientes de lo que hacen, y así, cuando preguntó cuál era la manera ideal de dividir una superficie a decorar todos respondieron que lo "mejor" era dividirla en cuatro campos; un examen de sus trabajos reveló que la división en tres o en seis era más frecuente: la explicación estaba en que para los Zuñi el 4 predomina en su mente por ser número sagrado. Y así, se probó, también, que las normas técnicas que daban los artistas no eran siempre observadas en la práctica y que había un cierto divorcio entre la cultura espiritual y las manifestaciones materiales.

¡Si aun nosotros hacemos cosas cuya explicación no podríamos dar! "Es la costumbre", decimos con frecuencia. ¿Por qué entrechocamos las copas al brindar?

Bunzel testifica cómo aparecen nuevas direcciones en la evolución de los estilas: Un ceramista de San Ildefonso que hacía cacharros negros y lustrosos consiguió un efecto mate por error $y$ lo explotó desarrollando un nuevo estilo que tuvo favorable acogida y gran auge. Otro alfarero hopi, Nampeyo, vió ceramios exhumados de las ruinas de Sityatki y los copió; muchos siguieron su ejemplo y se creó una "nueva" escuela.

Ahora, si suponemos que los restos de este estilo se encontraran mil años después, junto con restos de otros ceramios de San Ildefonso, ¿cómo debería relacionarlos el arqueólogo sirviéndose de la doctrina evolucionista?... "El artista fue bastante capaz de solucionar su problema técnico, $\mathbb{Y}$ do hizo, ne mediante un proceso de evolución, sino por una suptura radical con el estilo de su grupo. Si esto sucedió entre los primitivos actuales, a quienes podemos observar en trabajo, es razonable suponer que algo análogo puede haber ocurrido en el pasado..." Es lo que objeta una autora, ${ }^{2}$ y con razones parecidas expresa su desacuerdo con Haddon. Permítasenos responder que el argumento citado no invalida la teoría de la evolución de las formas artificiales. El rebrote de un estilo debe conectarse a la línea que lo inspiró, en este caso el estilo exhumado de las ruinas de Sityatki, y no a los que lo antecedieron inmediatamente en el mismo grupo artesano. Pero es claro que no podemos formar cronologías con la única herramienta del evolucionismo. Eso sería pedirle peras al olmo. Y muy ingenuo tiene que ser el arqueólogo que piense que un objeto de formas

2 Gladys A. Reichard: Form, and Interpretación in American Art. Proceedings of the XXIII International Congress of Americanists. 
"arcaicas" es más antiguo que uno de líneas barrocas tan sólo por esta condición. El mismo Haddon había hecho notar que hay formas embrionarias demasiado buenas para desaparecer completamente, y que al lado de las más evolucionadas sobreviven las que les dieron origen. Batracios y mamíferos coexisten en la actualidad.

La argumentación de Reichard puede resumirse así:

I Ninguno de los objetos con que los evolucionistas han formado sus series tiene cronología exactamente definida y rara vez podemos afirmar si el dibujo complejo se deriva del simple $\circ$ lo precede.

II Las interpretaciones se hacen desde el punto de vista del investigador y nada garantiza que vea del mismo modo que el autor de la obra. Donde uno hizo un pulpo, el otro puede ver una estrella o una flor. labras:

Repetimos las conclusiones de la autora en sus propias pa-

"Pero si nos decidimos a conservar una actitud imparcial y objetiva, y si conocemōs lás reacciones de los primitivos por lo menos respecto a su propio estilo artístico, surge una nueva cuestión: ¿Tienen alguhgvalor los estudios de un material puramente de objetos, tal como el que encontramos en los museos, sin datos sobre el modo como consideran los primitivos este arte suyo? $\mathrm{Mi}$ contestación será positiva: sí, lo tienen".

"Tenemos testimonio de que no todo lo que el artista siente se materializa en lo que hace. El material de museo nos muestra lo que hace en realidad, y analizándolo podemos hallar soluciones a muchos problemas que conciernen más al arte mismo que las teorías de su origen o interpretación. Se puede determinar el ajuste de forma y dibujo a la técnica. Las cuestiones de ejecución, como el tratamiento de línea, masa, color y fondo, pueden ser resueltas para áreas dadas. Habiendo practicado estudios detallados en motivos tan comunes como ojo, voluta, espiral, figura humana, etc., podremos estar seguros de evitar generalizaciones o formulación de "leyes", que si pueden ser válidas para un área, no admiten aplicación universal". 


\section{LA ARQUEOLOGIA}

Los conocimientos generales son, pues, una primera información para el arqueólogo. Teniendo en cuenta que, no sobre las "leyes", sino sobre el factor histórico gravita la importancia del método de la Arqueología, verá los datos documentales de la época proto-histórica así como los vestigios en el presente, antes de dictaminar respecto a sus hallazgos. Tiene más importancia para la pre-historia peruana un conocimiento de la historia del imperio incaico y de las costumbres de los indios actuales que una versación acerca de Egiptología, Asiriología y otros estudios clásicos.

Un palo, encontrado en yacimientos peruanos puede ser una takhyla (cavador), recobrado de uno neolítico del Viejo Mundo puede ser un bastón de mando. Objetos de la misma forma tienen significaciones diferentes según la cultura a que pertenecen. De allí que una antigüedad vale menos fuera de su contexto y que el cazador de curiosidades está mutilando los testimonios del pasado.

Pero el arqueólogo no es un simple coleccionista de especímenes. Estudiar los objetos artificiales noes la finalidad de la Arqueología sino un medio para reconstruir culturas pretéritas.

Dos ciencias viejas han tratado de la obra de arte: la Historia del Arte y la Arqueología. En realidad, la Arqueología no es estrictamente una ciencia; es una subciencia, 0 , simplemente, un método, una técnica puesta al servicio de una ciencia, de la Ciencia del Pasado. Pero mientras la llamada Historia tiene que hacer con testimonios escritos, la Arqueología se encarga de los objetos. Hay, así, una Arqueología Histórica, que trata de épocas y culturas históricas, y una Arqueología Prehistórica, o Paleo-arqueología como se la llama con poco éxito.

Podemos considerar a la Arqueología Histórica como inseparable de la Historiografía; la Arqueología Prehistórica está sola y necesita más de las Ciencias Naturales. Por eso pudo decir Kroeber que la historia y la arqueología del Perú son dos buques que navegan en la misma dirección, hacia el pasado más remoto, y que "antes del siglo XI de la era cristiana el buque de la ar- 
queología se separa, y debe seguir su curso solo, de la mejor monera que pueda". 3

La diferencia de los materiales que manipula y la de los métodos, que tienen que ser adecuados a ellos, es, repetimos, lo único que desune a las dos ramas del saber. "La ayuda que cada disciplina puede dar a la otra es tan evidente que no necesita explicación. Los límites de esta ayuda mutua tienen dos aspectos. Por una parte, la Arqueología es de lo más provechosa en la determinación de las condiciones generales dentro de un período y un área, y por consiguiente sólo satisface imperfectamente el deseo del historiador en lo que se refiere al conocimiento de los acontecimientos decisivos, en particular. Por otro lado, en civilizaciones como la andina, que se desarrolló sin escritura, el registro oral de memoria es demasiado momentáneo para permitirle al historiador penetrar tan remotamente en el pasádo como lo desea el arqueólogo.... así como para los períodos más recientes de documentación escrita, el historiador escasamente necesita la ayuda del arqueólogo". 4 -

Sin embargo, el estudio de los monumentos, el examen de los objetos, no es de valor inferior al de los documentos escritos: éstos son testimonios de criterio ajeno y significan una interpretación subjetiva, mientras que aquéllos informan inmediatamente el nuestro.

Por el lapso de vida de la humanidad que investiga, la Arqueología es "con celaciỏncanlal Historia "como el padre y el hijo", según las palabras de Morley.

Para examinar sus testimonios, la Arqueología, además de sus relaciones con el Folklore, el estudio del arte y las industrias, toma consejos de la Geología, la Geografía, la Botánica, etc. y del Estudio del Hombre. Es esta necesidad la que la hace oscilar entre las Ciencias Históricas y las Ciencias Naturales, y adoptar la personalidad doble del Dr. Jekyll y Mr. Hyde. ${ }^{5}$

Los dos principales métodos de la Arqueología son el estratigráfico y el tipológlco. El primero está copiado de la Geología y

3 A. L. Kroeber: Los métodos de la Arqueología Peruana, Letras, No 22, Lima, 1942, p. 211.

\& Kroeber, op. cit., p. 209.

5 Walter W. Taylor: A Study of Archaeology, Am. Anthrop. Memoir n, 69 (1948), p. 6. 
la Paleontologia; el último, es el estudio típico y propio de los objetos artificiales. Esto explica por qué unas veces se ha definido como rama de la Antropología, y otras como mero estudio del arte. Por épocas, cada uno de estos métodos ha pretendido prescindir del que debe ser compañero inseparable y colaborador. Especialmente en América, el arqueólogo sostiene que las interpretaciones estilísticas son muy subjetivas y que lo único "científi$\mathrm{co}^{\prime \prime}$, son las estratigrafías. Pero quienes piensan así olvidan que el criterio que sirve para separar los estratos es también un criterio tipológico. ¿Por qué separamos un estrato tiahuanacoide de uno incaico, cuando las características del terreno son idénticas? Sencillamente, porque un estrato - raras veces real- tiene objetos de un tipo, y el otro contiene objetos de tipo diferente.

"Debe recordárseles que sus resultados han de depender del trabajo de su pala, tanto como del de su cerebro", apunta agudamente de los arqueólogos un autor. ${ }^{6}$

Más radicalmente, este mismo autor dice que el arqueólogo cesa de serlo cuando utiliza los conceptos de la Etnología, la Mitología, el arte, etc.: "...Es la recolección de los materiales culturales la piedra de toque por la cual el arqueólogo, como arqueólogo, cae o se mantiene. Cómo manejar la información después de colectada es impertinente para él como arqueólogo, aunque le es muy pertinente como antropólogo, historiador del arte, filólogo, o cualquier otra cosqi.

Es obvio que la "información" a que se refiere no es sólo objetos, y aquí está lo grave: para recoger su información, el arqueólogo tiene que ser antropólogo, historiador del arte, filólogo y otras cosas más.

De cualquier modo, el análisis de los objetos artificiales del pasado cae también en la esfera de intereses del arqueólogo, aunque para ello deje la pala y se ponga el mandil del museólogo.

Los objetos artificiales tienen quizás una ventaja sobre el material del sociólogo, el del historiador, etc. Estos últimos son símbolos de ideas y conducta; los objetos artificiales son las ideas mismas y la conducta "congeladas". Como disciplina cuya meta final es la cultura, la Arqueología no puede satisfacerse con el objeto material. Si la cultura es organización de conducta aprendi-

6 Taylor, op. cit., p. 8.

7 Taylor, op. cit., p. 44. 
da, la conducta humana es lo que cuenta. Una máquina responde a elaboraciones mentales, y estas construcciones mentales 0 ideas son la cultura, no el montón de fierro. Pero el fierro está organizado en formas, y estas formas son la materialización de las ideas.

La habilidad peculiar del arqueólogo es "descongelar" sus testimonios. Para ello, sus mejores esfuerzos están dirigidos a las implicaciones del objeto más bien que al objeto individual en sí. "Fundamentalmente, parece haber dos requisitos en todo método arqueológico, y éstos guardan relación entre sí. El primer requisito es determinar cuáles son los fenómenos que tienen lugar en forma asociada, o no asociada, y en qué grado. El segundo requisito es traducir las relaciones de espacio de la información en relaciones de tiempo, de modo que el cuadro descriptivo pueda ser convertido en una narración ordenada". 8

Son estas asociaciones las que importan, y el objeto vale por sus potencialidades de asociación. Los objetos son el aparato material de la cultura, son los intrumentos materiales de la cultura y sus productos materiales, y por intermedio de ellos podemos llegar a la estructura "inmaterial". Porque la llamada cultura material no es exacta y escuetamente los objetos artificiales.

Es por medio de un entrelazamiento de comparaciones que e! arqueólogo "revela" el contenido de sus materiales. Sólo que la Arqueología, bajo la batuta dela Kullurkreislehre, parece haber estado ocupada principalmenteicoh irelaciones exteriores. "En lugar de construir una pintura cultural lo más completa posible para una manifestación particular dada, este punto de vista (el comparado) se dedica principalmente, si no completamente, a aquellos fenómenos que tienen significación comparativa fuera del sitio 0 componente. Descuida mucho del "cuerpo cultural local". 9

El autor que estamos citando protesta y reacciona contra dicho punto de vista; al hacerlo sigue la tónica del momento, una tónica "pertinente" al etnólogo, porque lo que recomienda es lo que preconiza el funcionalismo, aunque él lo llama the conjunctive approach: "El punto de vista conjuntivo... tiene como su principal meta la elucidación de conjuntos culturales, las asociaciones y relaciones, las "afinidades", dentro de la manifestación bajo in-

8 Kroeber: Los Métodos de la... p. 212.

? Taylor, op. cit., 95. 
vestigación. Tiende a trazar el cuadro más completo del pasado de la vida humana en términos de su ambiente humano y geográfico. Está interesado principalmente en la relación de item a item, rasgo a rasgo, complejo a complejo - para usar conceptos del Linton- dentro de la unidad cultural representada, y sólo subsecuentemente en la relación taxonómica de esos fenómenos a similares fuera de ellos". 10

Lo que tiene valor para la comparación no es el espécimen aislado sino el contexto cultural completo. Si un objeto sirve para eso, no es en su condición individual de objeto, sino como sepresentante de un tipo, es decir, por lo que tiene de más o menos representativo de un conjunto. Es un criterio de cantidad lo que hace más o menos importante la comparación, y tiene que haber implícito en el "ejemplar" una mayor concretización de abstracciones. Todo lo que los alemanes explicarían en una Typenbegrittlehre.

Evidentemente, para darle más valor al espécimen tenemos que elaborarle más relaciones, de modo tal que "ejemplifique" más contenido espiritual. He ahi por qué estamos obligados a desentrañar todas sus escondidas conexiones y significaciones. Cualquier actitud, parcial, siguiendo pautas de una escuela, es anticientífica.

Aun el difusionismo estudió incompletamente el fenómeno de la difusión por descuido delefuncionamiento de la cultura. "Un estudio completo del esparcimiento de cualquier nuevo elemento de cultura, los factores que han provocado tal esparcimiento, las reacciones a que este nuevo elemento ha dado lugar en diferentes sociedades, y las adaptaciones que han sido necesarias para su aceptación dentro de las diversas culturas, ayudaría mucho más a colocar los estudios de difusión sobre una base sólida que veinte estudios de distribución de caracteres en determinado punto de una época. Desgraciadamente, apenas existe un sólo estudio de esta índole hoy en día". ${ }^{11}$

Estas relaciones exteriores son la cronología y lo que se ha llamado también método geográfico, y que en realidad no constituye sino las implicaciones geográficas de cualquiera de los otros dos métodos, pues aunque la estratigrafía está preocupada esen-

10 Taylor, op. cit., p. 96.

11 Linton: Estudio del Hombre, p. 371. 
cialmente con sucesiones en el tiempo también investiga en sentido horizontal, delimitando el área de propagación de una cultura, su radio de acción y conexiones.

Cualquiera que sea la técnica empleada en el trabajo; cualquiera que sea el método que la oriente y cualquiera que sea la teoría que la inspire, la Arqueología comienza y termina en los objetos artificiales. Con la palabras de Stanley Casson: "La Arquelogía es el estudio del pasado humano, principalmente en lo que concierne a las actividades del hombre como fabricante de cosas, de artefactos, para usar el término técnico. El Homo sapiens activo, antes de que empleara su sapiencia en el propósito práctico de manufacturar objetos, no es de incumbencia del arqueólogo sino del antropólogo. Pero desde el momento en que el hombre picó su primer pedernal, él y su pedernal pertenecen al arqueólogo". 12

\section{FUNCIONALISMO}

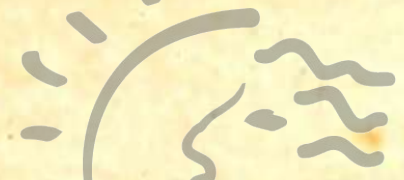

"Discutimos constantemente si un producto cultural que he mos encontrado en forma similar en dos áreas distantes, ha sido llevado a una desde la otra, o si ha evolucionado independientemente en cada una de ellas, La prueba depende de si la forma está determinada por el propósito y uso del producto, por el material de que está hecho,cpón das necesidades que satisface. En otras palabras, tenemos que preguntar siempre si la similitud en forma es debida a identidad en función, o si es tan accidental que no puede haberse originado independientemente sobre líneas paralelas". 13

En lo que respecta a la forma de los objetos materiales, el funcionalismo está representado por esa observación de uno de sus más conspícuos sostenedores. La forma, por si sola no dice mucho; es necesario considerarla en su contexto cultural. Las definiciones de forma, es decir, la descripción del objeto, dan una idea incompleta de su función, y dos objetos iguales pueden haber tenido aplicaciones diferentes. Estas consideraciones son observaciones al "criterio de forma" de los etnólogos alemanes.

12 Stanley Casson: Progresos de la Arqueología. Versión castellana (mecanografiada) de Emilia Romero, Lima, 1936.

13 B. Malinowski -Reviews, "Man", agosto, 1927. 
Efectivamente, los objetos tienen varios usos y aplicaciones, y es por un proceso lenta de especialización que divergen las formas primordiales hasta constituirse en otros objetos. N. C. Nelson (The Origin and Development of Material Culture, 1932) nos da una idea de las potencialidades de los instrumentos de piedra primitivos al publicar una tabla, reproducida por Herskovits, ${ }^{14}$ en la que se indica sus funciones y los principales útlles especializados, mayormente en metal, que sirven en nuestros tiempos para esas mismas funciones.

Nos encontramos, pues, con que si un mismo objeto sirve funciones diferentes, una misma función puede llevarse a cabo por dos objetos distintos.

Una lanza se distingue de una jabalina, en primer lugar, porque una es arma arrojadiza y la otra nó. Tratóndose de ejemplares evolucionados, la función puede haber afectado forma y tamaño, pero si examinamos ejemplares primitivos es difícil, si no imposible, saber su uso exacto. El criterio de forma, aplicado al espécimen será insuficiente para conocer de la función sin acudir a otros testimonios. Una piedra de moler es simple, y su clasificación depende de los movimientos que le imprimamos. El rodillo a empujar, como los metates centroamericanos; la mano de batán - maran peruano, con movimiento de mecedora; el verdadero rodillo europeo de pastelero, que rueda y aplana la pasta; la mano del almirez, que golpea verticalmenter y el molino de rotación vertical, todos tienen origen en la simple piedra de majar. Es aventurado señalar cuándo la función, esto es, el tipo de movimiento, influyó en la forma para especializarla en su trabajo: el espécimen no ostenta siempre huellas evidentes de éste.

Un estudio de muestras individuales es sólo un estudio estático de la forma. Ya vimos que la comparación de los ejemplares de una serie muestra el cambio e ilustra sobre el proceso. El funcionalismo se apunta el mérito de haber insistido en que lo fundamental es el rol que tiend la forma en el conjunto, y no la forma en sí. Lo importânte es la configuración, la relación entre las formas. La relación de una forma en un sistema y la relación entre diferentes sistemas constituye un orden; este orden es lo principal.

14 Melville J. Herskovits: Man and his Works, New York, 1948, p. 244 . 
El estudio de la cultura debe considerar en primer lugar el funcionamiento del todo y no la parcial consideración de un fragmento, porque la cultura no es un anárquico amontonamiento de partes sino una integral, un conjunto que trabaja como un reloj; y en el cual no hay ningún engranaje demás.

"The art and characteristic style of a people can be understood only by studing its production as a whole", había escrito ya Boas. La realidad etnográfica de un objeto no puede ser comprendida aisladamente aunque tengamos frente a nosotros ejemplares perfectos y auténticos: Una canoa, por ejemplo, -dice Malinowski- no es un simple objeto para determinado uso. "En el estudio de los propósitos económicos para los cuales una canoa se ha. hecho, de los varios usos a los que se le somete, encontramos la primera aproximación a un profundo tratamiento etnográfico. Más amplios datos sociológicos, relativos a su propiedad, descripción de quien navega en ella, y cómo lo hace; información respecto a las ceremonias y costumbres de su construcción, una especie de típica biografía de la embarcación, todo ello nos acerca más aún al real entendimiento de lo que significa para el nativo su canoa. Aun esto, todavía no toca la más vital realidad de una canoa nativa. Porque un barco, sea de corteza o madera, de fierro o acero, vive en la vida de sus tripulantes, y es para el marino algo más que un pedazo de materia con forma. Para el nativo, no menos que para el navegante blonco, una embarcación está rodeada por una atmósfera der romance i levantada sobreo una tradición y una experiencia personal. Es un objeto de culto y admiración, algo viviente, que posee su propia individualidad". ${ }^{15}$

En tratándose de culturas extintas, la reconstrucción se hará como mejor se pueda. Cuando se está frente a una viviente, empero, es imperdonable que la estudiemos examinando únicamente la obra material e ignorando otros aspectos de la vida de la sociedad. Nunça podremos decir hasta qué punto un objeto artificial está implicado en la religión, economía, organización política, etc., de un pueblo si no conocemos ese pueblo en todas sus actividades, si no conocemos el entramado en su totalidad. Comprender la naturaleza de la cultura antes de someterla a cualquier otro tipo de investigación es funcionalismo, decía Malinowski, y se mo-

15 B. Malinowski: "Argonauts of the Western Pacific", Londres, 1932, p. 105. 
faba de "la satisfacción perversa de encontrar anomalias aisladas y peregrinas del comportamiento humano", cosa un tanto injusta porque todo etnólogo sabe de la relatividad de las anomalías, y quien trabaja en el campo no considera ya la Etnología como mero análisis y recolección folklórica de objetos y costumbres curiosos y exóticos.

Más injusto es todavía Malinowski cuando desprecia la tecnología, los estudios de reconstrucción y los de distribución, señalando únicamente las relaciones internas dentro de un esquema dado; aferrándose a sus secciones transversales de la cultura y descuidando la naturaleza- tradicional de todo el complejo; olvidando que cultura, por definición, es la transmisión de patterns de generación en generación, y por lo tanto, un fenómeno histórico, y de individuo a individuo, y por lo tanto un fenómeno de difusión. Es antidistribucional y antihistórico, había observado Lowie.

Lo importante para Malinowski son las instituciones, cuerpos organizados de actividades llevadas a cabo por cada grupo social en la satisfacción de una necesidad biológica primaria, en conexión con un habitat y con ciertos objetos materiales y un sistema de ideas derivadas.

"Hemos establecido, pues, que la totalidad de un procese_cultural, que comprenda el substrato material de la cultura, esto es, artefactos; lazos sociales humanos, esto es, modos estandardizado de conducta; y actos simbólicos, esto es, de influencias de un organismo sobre otrosipor medio de reflejos de estímulos condicionados; es una totalidad que no podemos cortar aislando objetos de la cultura material, pura sociología, o lenguaje como un sistema de contenido propio". ${ }^{18}$

Así, de ese modo, la cultura, como cuerpo vivo, no puede consentir amputaciones en sus órganos principales.

El, énfasis en que la cultura es una entidad muy distinta.a la suma de süs componentes, caracteriza pues, el funcionalismo: "Todas las partes del sistema social funcionan juntas con un grado suficiente de armonía o consistencia interna", escribía otro de sus notables sostenedores. ${ }^{17}$

Es en defensa de.este arganismo que se ataca al evolucionis:mo tanto como a hístoricismo; Ja la selección de hechos como a la

16 B. Malinowski: A Scientific Theory of Culture, p. 154.

17 Radcliffe- Brown: On the Concept of Function in Social Science, Am. Anthrop. v. 37 (1935), p. 397. 
preocupación por lo que ha sido y ya no es. "Por descuido del análisis funcional de fenómenos lingüísticos vitales, Morgan extravió la investigación antropológica por generaciones. También Graebner, enarbolando un pueril o falso análisis de la cultura para poner los fundamentos de lo que consideraba un panmündial y fool-proof difusionismo, ha creado una consideración antifuncional de imbecilidad de primera clase. Graebner supone primero que es posible aislar detalles de su contexto. Después define la forma como completamente desconectada de su función... De allí que para Graebner sean metodológicamente importantes aquellas características culturalmente insustanciales". ${ }^{18}$

En uno de sus artículos, ${ }^{19}$ Lowie toma la defensa de Graebner "quien sin duda merece bastante crítica legítima" pero no esos epítetos, e indica que el investigador in situ que Malinowski condena ya no existe, y que su asalto a los vestigios no hace sino repetir lo que Marett dijo en 1918 en Psychology and Folk-Lore (26, 101, 1920); añade que el que cada cultura sea un sistema cerrado, no pasa de ser un dogma, y que más bien ies un conjunto artificial forjado por conveniencias de la averiguación. El funcionalismo es un programa para estudiar vínculos intraculturales. Pero si hemos de considerar la cultura en su totalidad, no debemos pararnos en los fenómenos que hay dentro de ella sino también considerar los que están fuera y así no circunscribirnos a la actualidad sino del mismo modo temontarnos al pasado.

"Ciertamente muchos del losi elementos coherentes en la vida de un pueblo no son azares concomitantes, pero no se ha probado nunca que todos los rasgos estén eslabonados, y los intentos hechos hasta ahora para demostrar integración no han ido nunca más allá de mostrar que, digamos, el arte está conectado con supernaturalismo, o los propósitos económicos con ideas mágicas... Finalmente, mientras es verdad que ningún hecho aislado es significativo, no se sigue de ello que las únicas correlaciones vitales se encuentran dentro del supuesto sistema cerrado de una cultura particular". 20

Otro de los errores de Malinowski es suponer que todo tiene función en la cultura y que lo que no la tiene desaparece, trecha-

\footnotetext{
18 Malinowski: A Scientific..., p. 149.

10 American Anthropologist, v. 48: 1 (1946), p. 118 y 119.

R. Lowie: The History of Ethnological Theory, New York, 1937,
} p. 143. 
zado por el organismo: "Cuanto mejor se conoce determinado tipo de cultura, tanto imenos supervivencias parece existir en ella". 21

No cabe duda de que en todos los contactos culturales hay ingerencias_____desintearaciones_provocadas por la interferencia de elementos que se disputan un mismo puesto. El hecho de que los contactos traigan desajustes, prueba que las culturas funcionaban como un organismo y que las crisis provocadas por los elementos extraños equivalen a la intromisión en la máquina de una rueda inútil o de otro resorte motor. Sin embargo, siempre hay compromisos: elementos pocos vitales sobreviven y vegetan al lado de los órganos que los han subrogado; aun puede darse el caso de que un producto teratológico subsista con dos sistemas digestivos. Esto, se dirá, justifica como normal un cuerpo provisto de un solo corazón y un solo cerebro. Pero ¿qué garantiza que el símil seo exacto? Precisamente, el moderno concepto de civilización supone la coexistencia de muchos modos de vida, la convivencia sin estorbo de varios elementos homólogos de cultura.

Como el ojo pineal, un órgano puede perder una función pero adopta otra, supone el funcionalista, y así la corbata ya no sirve para amarrar el cuello de la camisa, puesto que hay un botón en su lugar, mas ahora es símbolo de clase social; los botones de la manga del saco no cierran la abertura, pero la decoran; el ojal de la solapa no se abotona, pero sirve para colocar una insignia.

Con esta lógica todo sirve aunque nos privamos así de un criterio importantísimo en el estudio de la cultura: la relación entre forma y función.

-Yo afirmo que la forma está siempre determinada por la función y que en tanto no podamos establecer tal determinismo, los elementos de forma no pueden ser usados en un argumento científico". 22

¿Y qué hay de las formas vestigiales sin función, o con otra función que suplantó a la que las determinó? ${ }^{23}$ Las supersticiones son manifestaciones culturales que no podemos ignorar como supervivencias aunque les reconozcamos nuevas funciones.

21 Artículo "Culture", en la Encyelopaedia of Social Sciences, v. 4 (1931).

22 A Scientific Theory... p. 149.

23 Margaret T. Hodgen: The Doctrine of Survivals. Londres, 1936. 
Vamos a acudir a Boas, retrospectivamente, para apoyarnos. La cita se refiere a la función fisiológica, y es pertinente, ya que el funcionalismo compara la cultura al organismo humano: "La función depende de la estructura y de la constitución química del cuerpo y de sus órganos, pero no de modo tal que esté determinada por ellos. El mismo cuerpo funciona de diferente manera en diferentes momentos. Mientras las características anatómicas del cuerpo son regularmente estables por espacios de tiempo bastante prolongados, sus funiones son variables". ${ }^{24}$

Una de las más recientes críticas al funcionalismo, ${ }^{25}$ inspirada quizás por el hecho de que Malinowski era profesor en la School of Economics de Londres, identifica su doctrina con el hedonismo, y le censura que como todos los economistas, haga derivar de las necesidades e impulsos biológicos el comportamiento social sosteniendo que los imperativos culturales no son sino necesidades secundarias salidas de lo orgánico. Con las palabras de Marx (Crítica de la Economía Política, 1859): "La vida material determina el proceso de las manifestaciones intelectuales de la sociedad".

Al igudlar las necesidaes biológicas y las instituciones se justifica todo sistema cultural como bueno: todas las costumbres serían naturales, necesarias, justas y dignas de perdurar; ninguna sería ni absurda ni perniciosa. Además, como expresiva de distintos grupos, la moral sería relativa.

"El funcionalismo notaccon pavor y admiración que cada parte es necesaria para la existencia continua de una sociedad dada en su estado dado". ${ }^{26}$ La sociedad estaría dotada "naturalmente" de poderes regenerativos, tendería al equilibrio, pero no habría equilibrio errado. Una especie de salud social sería lo ingénito a cualquier grupo. No podría haber "cultural lag", como no habría "survivals". El contacto cultural solucionaría las inconsistencias con la desaparición de una de las culturas en fricción, como se solucionaría un conflicto interno con la eliminación del elemento disturbante.

24 Boas: The Mind of Primitive Man, New York, 1911, Macmillan, cap. VII.

25 Dorothy Gregg y Elgin Williams: The Dismal Science of Functionalism, Am. Anthrop., .v. 50, n. 4: 1 (1948).

26 Gregg y Williams, op. cit., p. 601. 
Lowie, empero, ya había notado que por muy bien estructurada que parezca una cultura, no trabaja $\propto$ la perfección, y que aun sin intervención de elementos culturales extranjeros se producen desajustes.

En suma, los funcionalistas, como los economistas, no podrían cambiar la naturaleza humana y habrían creado, sin embargo, un Homo economicus:

"La actitud científica, implicada en toda tecnología primitiva y también en la organización social y en la organización de las empresas económicas primitivas, aquella confianza en la experiencia del pasado con miras a actividades futuras, es un factor integral que debemos suponer ha estado en función desde los más antiguos orígenes de la humanidad, desde cuando las especies iniciaron su carrera como homo faber, homo sapiens o como homo politicus". ${ }^{27}$

\section{TIPOLOGIA}

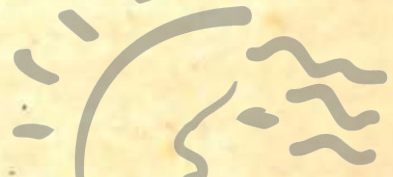

Pero el Homo faber fue dejado de lado; el funcionalismo censuraba la mentalidad tecriológica. "Lo notable entre los énfasis funcionalistas es la acentuación de los aspectos psicológicos de fa cultura", afirma Lesser, ${ }^{28}$ otros de los reivindicadores del evolucionismo. Puede afirmarise que las ctendenciassactuales de los estudios antropológicos los mueve alrededor del aspecto psicológico de los fenómenos sociales. Betty Meggers ${ }^{29}$ ha hecho un examen minucioso de este cambio de orientación que, sin duda, ha de ser muy benéfico puesto que explica al hombre en función de su cultura y abandona, al menos por el momento, esa excesiva consideración de su bagaje innato. Desde los esfuerzos de Rivers, que procuraba sintonizar los aportes de la Etnología y la Psicología, hasta el nuevo psico-análisis hay un largo camino recorrido.

Las diferencias entre las gentes que pueblan las variadas regiones de la tierra no son únicamente de apariencia; hay diferencias en opiniones, diferencias en actitudes y diferencias en la con-

27 Malinowski: A Scientific Theory..., p. 10.

28 A. Lesser: Functionalism in Social Anthropology, Am. Anthrop. v. 37 (1935).

29 B. Meggers: Recent Trends in American Ethnology, Am. Anthrop. v. 48 , n. 2 (1946). 
ducta. La cultura es el factor condicionante que por medio de la educación y el entrenamiento transforma la fisiología del hombre. Para comprender al individuo no nos basta un estudio somático: su anatomía no puede explicarlo completamente; tenemos que estudiar su psiquismo a la luz del determinismo cultural, es decir, a través del examen de todo el proceso de su modelamiento por el ambiente social.

Estas consideraciones son de tal peso que toda otra ha quedado relegada a segundo plano.

La cultura es una ficción estadística; la sociedad no es el grupo material de hombres que la compone, y es también una abstracción. La única realidad es el individuo $y$, por lo 'tanto, el.foco más apropiado para el estudio.

Un equilibrio saludable, sin embargo, es de lo más necesario, y lo encontramos en las palabras de Feibleman: 30 ..."Que los seres humanos son parte de la cultura, pero que sin herramientas e instituciones no habría cultura, como no la habría sin seres humanos". .

Vale decir, una realidad tangible es el individuo, y otra los objetos artificiales. Podríamos agregar que la individualidad, o mejor, la personalidad es también una abstracción, y lo único ponderable serían los objetos artificiales.

"El estudio de la tecnología es esencial para una comprensión de la cultura, del mismo modo que la comprensión de las bases materiales de la yida social ies indispensable, a aquellos que tratan de la conducta del grupo humano... El equipo técnico de un pueblo figura, más que cualquier otro aspecto de su cultura cuando se hacen juicios corrientes sobre su avance o retraso. Hay varias razones para estos juicios, pero en esencia pueden atribuirse al hecho de que la tecnología es el único aspecto de la cultura susceptible de evaluación". ${ }^{31}$

Y a la inversa: para comprender la nuturaleza de lo artificial hemos de conocer antes al hombre físico, como lo preconiza el funcionalismo y toda la escuela sociológica francesa, que halla la expresión más simple de los móviles culturales en el hambre y el amor. Incluso Harrison, quien desaprobaba a Malinowski, no pu-

30 James Feibleman: The Theory of Human Culture, New York, Duell, Sloan and Pearce, 1946, p. 95.

31 Herskovits: Man and his Works, p. 241. 
do encontrar mejor punto de partida: "Como tecnólogo —declarótrató primero de las necesidades y propósitos materiales del hombre, que podemos agrupar en un relativamente pequeño número de tipos de satisfacciones que incluyen tanto necesidades reales como falsas". 32

Estas falsas necesidades son las necesidades secundarias de los funcionalistas, las que los diferentes tipos de cultura crean: pueden traducirse también en objetos artificiales. Así el prestigio o la influencia social pueden estar representadas por lujo y riqueza material. Y hay objetos, es claro, que no son la expresión llana e inmediata de una primera necesidad biológica, sobre ellos no puede iluminarnos mucho el saber de la naturaleza homínida de la realidad que los creó y los utiliza, sino que un conocimiento de los imperativos culturales derivados es imprescindible.

Los esquemas del funcionalismo son importantísimos por esto. Desde el estímulo biológico, a través de los estímulos derivados, ván a las técnicas, a los artefactos y a las series instrumentales antes de. alcanzar las satisfacciones integrales. Como se ve, no cierra del todo las puertas a un examen tecnológico, aunque el tono de su insistencia sobre los aspectos integrales parezca indicarlo.

"La brillantez de sus resultados no debe deslumbrarnos hasta el punto de que rechacemos como inferiores aquellos métodos y temas que Malinowski tocá sóle raras veces y que en lo abstracto excluye arbitrariamente". ${ }^{33}$

(Continuará)

82 W. S. Harrison: Concerning Human Progress, p. 1.

33 Lowie: Historia de la Etnología, traducción castellana, p. 294. 